\title{
Learning Experiences of Frustrated-Level Readers in the Implementation of Self-Learning Modules in the New Normal Education
}

\author{
Honey Lyn P. Valentos ${ }^{1}$, Ronald S. Decano ${ }^{2}$ \\ ${ }^{1}$ Graduate Student, Doctor of Philosophy in Educational Management, Davao del Norte State College, Philippines \\ ${ }^{2}$ Dean, Institute of Advanced Studies, Davao del Norte State College, Philippines
}

\begin{abstract}
The turn of a single page is the beginning of knowledge. Reading is known as one of the most vital skills that a person should have. The aim of this descriptive qualitative phenomenological study was to explore the learning experiences of Frustrated -Level Readers in the implementation of selflearning modules. Insights, opinions and ideas were sought from ten (10) Grade 8 students through Key Informant Interview. Responses were recorded, transcribed, coded analyzed, and categorized into themes. Six emergent themes were generated, namely: (1) Increasing reading comprehension (2) Providing Filipino-English Dictionary (3) Enhancing interest in reading (4) Repeated reading (5) Acquiring support from teachers and parents (6) Providing supplemental learning resources. Findings revealed that the most challenging experiences met by the Frustrated -level Readers are the lack of comprehension and insufficient learning resources. With these findings, the school administrator and reading teachers should provide necessary learning strategies and supplementary resources to increase reading comprehension.
\end{abstract}

Keyword: Reading comprehension, Self-paced learning, New Normal Education

\section{INTRODUCTION}

$\mathrm{W}^{\mathrm{s}}$ e all read regularly. It's done for both fun and learning. Reading skills are critical for people since they help them understand what they're reading. It's impossible to expect kids to be good readers if they don't know how to read. As a result, individuals cannot pass examinations at their speed because they lack understanding (Kaya E., 2015).

For this reason, Brevik (2019) claims that reading comprehension is a multi-faceted process that involves interactions among many variables such as context, reader activity, and the text itself. Reading comprehension is defined by Snow (2002) as a process in which the reader extracts and derives meaning while interacting with written material.

The reader, text, and activity are all mentioned by Snow (2002) as being essential components of reading comprehension. According to Urquhart and Weir (1998), reading is a process through which people acquire and understand information. According to Anderson (1999), the reader is an active participant in the interaction with the reading material throughout the reading comprehension process (Sepehr Safaie, 2020).
The increasing need for literacy is one of the leading indicators of current reading problems. A growing competitive economy is causing instructors in the Philippines to be worried about the vast number of students who may be harmed in their career or social prospects if they do not have the reading abilities necessary to keep up. The demands on higher literacy in a technology culture are rising all the time, with more serious implications for individuals who don't meet them (Aquino \& De Vera, 2018).

When an unprecedented global COVID -19 epidemic occurs, it creates a great deal of anxiety for people across the globe. This creates a health and economic catastrophe. The present state of affairs has had a significant impact on educational systems across the globe.

To stop the spread of the coronavirus, all schools and institutions in the area have been closed. Students, teachers, and parents all suffer when schools are closed. Distance learning is a way to keep the educational system going indefinitely. In the year 2020, Tadesse and Muluye

But health and safety of students, as well as teachers, must be safeguarded at all times. Education must keep people informed and offer them hope. It must take part in returning activities in the nation to normality. It must help our learners grow. And it must restore their lives to normal (DO 007, s. 2020).

In Manay National High School, among all learning delivery modalities introduced through the online survey, Distance Learning (Printed) or SLMs came out to be the most preferred by the parents because it does not need electronic devices, internet connection and more importantly it is economically wise for the parents since it cost a small amount of money.

Alongside, self-paced learning modules (SLMs) are selfcontained, self- instructional, self-paced, and interactive learning resources for public schools intended for learning as a specific topic or lesson where the learner interacts actively with the instructional material rather than reading the material passively. (DO 018 s, 2020)

This fundamental purpose of the study was to discover the challenges met by the Grade- 8 Frustrated-level Readers in implementing Self- paced Learning Modules for SY 20202021. Likewise, this study sought to ascertain specific 
interventions that would address the needs of struggling readers who have difficulty in this new routine learning modality.

\section{RELATED LITERATURE}

Flores (2009) stresses the significance of being able to read. Reading competence may open doors to economic opportunity, social prestige, increased personal enjoyment, and increased self-respect for those who can communicate successfully verbally and in writing in several formats and for a variety of reasons. As a result, academic achievement depends on the student's ability to read and understand written material.

According to Resurrection (2010), reading is an essential instrument for learning because it helps students reason, analyze, assess, and evaluate what they've read. Having the ability to read is essential for a successful life as well as for studying the curriculum subjects. For pupils, knowing their reading performance is critical, according to Miller (Alonzo, 2005), who says that it is the key to learning. Reading helps you get information that you can utilize to create more knowledge. Comprehension is the process of extracting meaning from written information and then rediscovering that meaning (Aquino and De Vera, 2018).

\section{METHODOLOGY}

\section{Research Design}

For this study, qualitative content analysis for its research design was employed, which as usual allied with interviews and survey design techniques through in-depth interviews as a way to reinforce and evaluate findings over a broader scale. A qualitative research method was used in identifying and exploring the challenges met by the Frustrated - level Readers in the implementation of Self-paced Learning Modules (SLMs) for SY 2020-2021.

\section{Research Locale and Sampling}

The ten (10) Grade- 8 students who were categorized in frustration level based on the results of PHIL-IRI tool last SY 2019-2020 were chosen as key informants. Purposive sampling was utilized in the selection of respondents (Creswell, 2012). A researcher-made interview guide was employed to gather the data needed, which was enhanced by external validators.

\section{RESULTS AND DISCUSSIONS}

The informants unveiled the challenges met and how they coped up in answering the self-paced learning modules (SLMs) in this new regular education despite being frustratedlevel readers. The responses provided by the participants paved the way to create essential themes, and these were supported and justified by the statements of the informants. Six (6) themes were generated from the experiences of Grade -8 students under frustrated level- readers, namely: (1) Poor reading comprehension (2) Lack Filipino-English Dictionary (3) Lack of interest in reading (4) Repeated reading (5)
Acquiring support from teachers and parents (6) Lack of supplemental learning resources

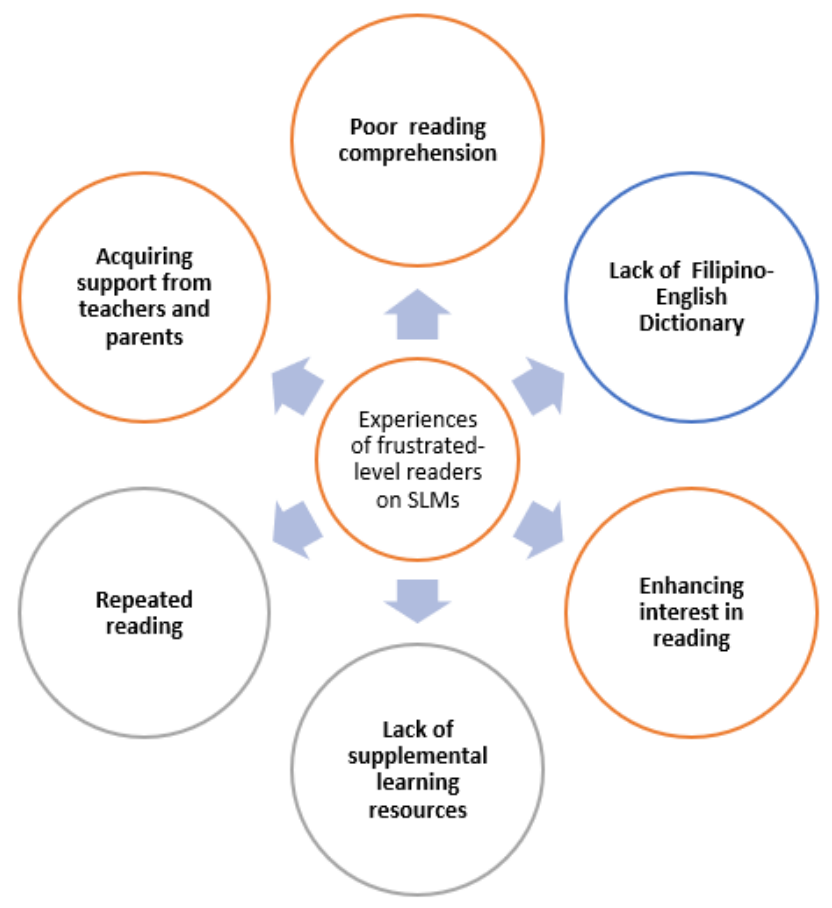

Figure 1: Themes Generated by the Researcher

\section{Poor reading comprehension}

Reading comprehension plays a vital role in self-paced learning. As such, the implementation of self-paced learning modules due to the pandemic crisis has greatly affected the students, especially the frustrated-level readers. The biggest challenges met by the frustrated level readers in the implementation of SLMs are the complex and unfamiliar words they encounter. As to the responses of informants that they found difficulty in understanding the text, $100 \%$ of the informants stated that they lack comprehension on the text they read.

Data gathered tell that reason why they could not understand what they read because they had a hard time understanding the text itself. To date, the frustrated-level learners learning potentials are more put to the test due to the implementation of self-paced learning. However, to overcome the difficulty met by the frustrated level readers, it is highly recommended that language teachers intensify the reading intervention program and devise reading strategies to help increase the reading comprehension of the students amidst this pandemic crisis.

When Janzen and Stoller (1998) did a similar study, they found that there were ten processes or strategies for reading comprehension. These were: (1) determining the purpose of reading; (2) previewing; (3) prediction; (4) questioning; (5) checking predictions; (6) finding answers to questions; (7) summarizing; connecting one part of the text to another, and (8) recognition of text structure. " 
As described by Steeve Mackee (2012), reading comprehension is the capacity to comprehend a text, evaluate the material, and correctly interpret what the author is saying. As a result, the capacity to read, comprehend, process, and remember what one has just read is referred to as reading comprehension.

Moreover, comprehension is the common thread in instruction across all subject areas. In reading, it is what gives the meaning of the words. Likewise, words in different contexts or settings (e.g., genres of literature, informational text structures, etc.). In various typically content areas (science, social studies, health, etc.), comprehension allows us to understand information about a topic. Thus, comprehension is critical throughout the curriculum. Because its variations are not intuitive, the forms of comprehension and their application across types of reading material must be taught explicitly. "Reading Comprehension: Essential for Sustainability, 2009"

\section{Lack of Filipino-English Dictionary}

Understanding vocabulary improves reading comprehension and fluency because it helps to activate and develop background information needed to create connections between the text and the reader's own experiences.

Key informants cited the absence of vocabulary terms as the cause for their difficulty comprehending the material. So instructors must focus on teaching frustrated-level readers how to decode new and challenging words by using a dictionary.

Likewise, based on the responses, it is highly recommended that Filipino-English Dictionary must be provided for them to be used in self-paced learning.

Using dictionaries, Sergio Medina (2019) believes, may assist pupils in better comprehend texts, especially when decoding complex words. Some studies have also demonstrated that utilizing a dictionary may assist students in enhancing their reading comprehension while improving their vocabulary. According to studies, children who utilize dictionaries do better on reading comprehension and vocabulary (Summers, 1988).

Also, they've shown that using a dictionary may assist with lexical retention since readers pay greater attention to words they look up in dictionaries. Finally, studies have demonstrated that using dictionaries used as a teaching strategy for enhancing vocabulary helps students comprehend what they read more efficiently.

\section{Lack of interest in reading}

Students' academic performance is enhanced when they have interests in reading. So kids must like reading if they are to do well in school. In different reading materials, such as academic books, periodicals, newspapers, and journals, one may access a wide variety of information via reading. Selflearning modules' deployment required a high level of reading motivation.
According to the informants' answers, the lack of interest was significant in their inability to comprehend the material. Their reading interest waned when they were forced to study alone without the company of classmates and friends, particularly in the modular learning setting. Furthermore, students' lack of interest in reading was hindered by exposure to technology, where they spend much of their time playing online games.

Reading interest is described by Mc Kool (2007) as reading is done outside of the school premises. According to US Department of Education (2005), reading interests include whether students read in their free time, at home, or at the library and how often they read in those settings. The number of books students read in a month and the number of times they read a week and their preferred genres and kinds of English reading materials all contribute to their reading interest.

\section{Acquiring support from teachers and parents}

Parents' involvement with reading activities at home has a significant favorable influence on reading achievement, language comprehension and expressive language skills. When children experience early reading with their parents it prepares them for the benefit of formal literacy instruction.

On the other hand, teachers have a pivotal role in helping children develop and maintain a positive attitude towards learning and literacy. Despite, the reading difficulty experienced by the informants, they believed that their teachers and parents have been a great help improving their reading difficulty. Through their continuous hard work, the reading development of students had significantly improved. Motivated readers read more, use more complex cognitive strategies, and thus become better readers.

Developing young readers learning to read doesn't happen magically. Parents and teachers play essential roles in developing young readers. Supporting a child is best accomplished when parents and teachers share standard methods and basic understandings about the reading process.

Bano, et.al (2018) cited that the parents and teachers can guide children in setting the purpose of reading, making them conscious about what and why they read.

Jose \& Raja (2011) posited that teachers are the prime source for students cultivating the reading habit. Their advice and encouragement will go a long way in the achievement of the goal. Teachers need to train young learners in pronunciation, enrichment of vocabulary, acquisition of fluency and accuracy. They can execute this task only when they have the competence to play their role effectively. Special assistance may be given to students concerning selecting materials for reading based on their age, time and capacity and determine their reading levels. Teachers should insist on the importance of reading the hour in school or college library at least thrice in a week. 


\section{Repeated Reading}

Repeated reading is the practice of having a student read the exact text repeatedly until their reading is fluent and errorfree. Repeated reading was initially been used to support students with learning disabilities that impacted their reading until educators realized that most students can benefit from this method.

One of the ways informants did when they could not understand what they read was to repeat reading the text until they could gradually understand the text. Even though it would still be difficult for them to understand, they somehow understood the meaning of what they read through repetitive reading.

Dotson (2017) stated that while several strategies improve fluent reading, repeated reading has been found positively to impact students' reading fluency (McKenna, 2002). Successive reading of the same passage can lead to faster reading times, enhanced sight words and decoding abilities, and improved phrasing through the successive reads; each of these improvements also can lead to an improvement in student self-esteem and confidence levels.

Lapp \& Gainer (2010) repeated reading strategy was indeed successful in improving comprehension abilities, participants improved their accuracy when reading orally. For each passage's second reading opportunity, five of the participants decreased their error totals while two remained at the exact error total. In contrast, only $9 \%$ of participants showed a gain in errors when comparing the first reading to the second reading of the same passage. This data set validates the participants' study goal of decreasing errors for the second reading and an original stated goal of the repeated reading strategy.

\section{Lack of supplemental learning resources}

Learning resources refer to any person or material, whether acquired or locally produced with instructional content or function used for formal or informal teaching/learning purposes.

Learning resources may include, but are not limited to, print and non-print materials; audio, visual, electronic, and digital hardware/software resources; and human resources.

It was revealed from the data collected that, aside from the printed modules given to the informants they plead for learning resources that would serve as their guide in answering self-paced learning modules.

Likewise, informants asked for audio - video recorded lesson aligned in the activities in the SLMs, radio broadcasting if possible, especially for complex subjects like Math, Science and English.

Zufar (2020) posited that, basically learning resources are the foundation of knowledge in learning. In this era of efficiency, learning resources are very abundant and quickly found. The internet is one of the learning resources that is inseparable from the search for knowledge (Lau et al., 2018). Consequently, it creates a change in learning resources that used to be physical forms, such as books, magazines, and others, to become non-physical, such as internet, applications, and, most importantly, social media (Kilpatrick, Sengchanh, Namvongsa, \& Gray, 2019).

\section{CONCLUSION}

In light of the data gathered from content analysis and based on the study's findings, succeeding conclusions were drawn. Teachers have a significant role in improving the reading difficulties of the students. A dedicated and committed teacher might have a significant impact on the students' academic life, especially on improving their reading comprehension.

For the students to improve their reading level, teachers should try to find engaging and meaningful reading activities. Reading enhancement should be a continuous process as it is a significant partner in their academic related activities. School administrators and reading teachers must work hand in hand to implement projects and programs that would address the needs of the struggling readers for them to become independent readers.

Alongside, constant practice makes more reading understandable. If students keep on reading, there is a bigger chance that their reading difficulties will be eliminated.

Parental Guidance is necessary in the students' reading improvement. Parent's support is the most significant factor contributing to the success of the school's efforts towards increasing the reading potential of every struggling readers on this drastic change happen nowadays in the educational setting caused by pandemic crisis.

\section{RECOMMENDATIONS}

1. On the part of the students, they should consider reading as a passion and habit.

2. To address the needs of the frustrated-level readers school administrator and reading teachers should religiously implement the proposed reading intervention project entitled "Project $\mathrm{RPH}$ " which means making Reading a Passion and Habit to be initiated by the teachers to help these struggling readers find meaningful learning experiences in the implementation of self-paced learning due to the pandemic crisis. Project RPH includes the provision of English-Filipino Dictionary, audio-video lesson and additional reading materials. Also, more stories and reading materials should be created to further enhance students' reading abilities.

3. After which, teachers may require students to enhance reading activities such as book reports, journal writing, reading logs, and other reading tasks aside from their daily lessons.

4. The use of PHIL-IRI should be continue in conducting post-test. 
5. The reading coordinator may further study reading comprehension and consider other skills like sintering, applying, creating, and the like.

6. It is recommended that reading competition be included during the English festival as it ignites students' interest and will add up as a reading culture in school.

\section{ACKNOWLEDGEMENT}

This work will never reach this point without JESUS, the source of all my wisdom and strength. Thank Lord for letting me experience this hard but very fruitful endeavor. Thank you so much for providing and touching these people that made my scholarly journey possible. Dr. Ronald Decano, research adviser and the Dean of the Graduate School of Davao del Norte State College for his encouragement to finish this research. The panel examiners, who made valuable recommendations to enhance this manuscript. To ma'am Gel Marie Tiboron and her brother Prof Van M. Buladaco for helping me submit my paper for publication.

Likewise, I would like to extend my gratitude to my supportive husband Julius and my son Keihnt Juls for being my inspiration and to their support. To my best friend Ninang Marjorie P. Caslib and her family for all the help extended and my new Ka- Super friends from Panabo National High School. My paper made my paper possible to my students for letting me invade their thoughts and pouring out their sincere insights to my interview questions. In one way or another, they all have kept me moving towards finishing this research study. Thank you so much. To God be all the Glory and Honor. With much love and thanksgiving,

Honey Lyn P. Valentos

\section{REFERENCES}

[1] Aquino, M. \& De Vera, P. ( 2018) "Development of Learning Material for Grade 7 Struggling Readers," Pangasinan State University - School of Advanced Studies, Urdaneta City Pangasinan

[2] Bano, et. Al (2018) Perceptions of Teachers about the Role of Parents in Developing Reading Habits of Children to Improve their Academic Performance in Schools. Journal of Education and Educational Development Reading Comprehension: Essential for Sustainability. Sustainability Series Number 8 • September 2009 https://www2.ed.gov/programs/readingfirst/support/readlores.pdf

[3] Creswell, John W. (2013). Qualitative inquiry and research design: choosing among five approaches / John W. Creswell. - 3rd ed.

[4] Jose \& Raja (2011).TEACHERS' ROLE IN FOSTERING READING SKILL: EFFECTIVE AND SUCCESSFUL READING. -manager's Journal on English Language Teaching, Vol. 11No. 4lOctober - December 2011 file://C:/Users/User/Documents/EJ1071046.pdf.

[5] Kaya, E. (2015). The Role of Reading Skills on Reading Comprehension Ability of Turkish EFL Students. Üniversitepark Bülten, 4(1-2), 37-51.

[6] Sana (2013) "Importance of Early Reading Intervention," ESSAI: Vol. 10, Article $30 . \quad$ Available at: http://dc.cod.edu/essai/vol10/iss1/30

[7] Sepehr Safaie (2020) The effects of explicit and implicit teaching of connectors on the reading comprehension performance of Iranian EFL lea rners, Cogent Education, 7:1, 1777806, DOI: 10.1080/2331186X.2020.1777806

[8] Sergio Medina (2019) Effects of Reading Strategy and Dictionary Instruction in an Undergraduate Foreign Language Reading Comprehension Group a https://doi.org/10.17227/folios.5010226

[9] Shinawatra International University, Bangkok, Thailand https://link.springer.com/content/pdf/10.1186/2229-0443-2-145.pdf

[10] Steve Mckee (2012) | P a g e Reading Comprehension, What We Know: A Review of Research 1995 to 2011. Language Testing in Asia Volume two, Issue one February 201245

[11] Tadesse, S., \& Muluye, W. (2020). The Impact of COVID-19 Pandemic on Education System in Developing Countries: A Review. Open Journal of Social Sciences, 08(10). https://doi.org/10.4236/jss.2020.810011 